\title{
Crowdfunding Towards the Future: The Need of Different Research Perspectives
}

\author{
DANIELE PREVIATI \\ daniele.previati@uniroma3.it \\ University Roma Tre
}

In serving as editor of this issue of pIJ on crowdfunding, I want to pursue two main goals. Obviously, on the one hand, it is necessary to underline the relevance of each of the accepted papers hereafter published, thus presenting - from my point of view - the most fascinating contributes to the academic debate about this kind of financing channel. On the other, I think that it is even more useful for future research development to try to depict a possibly more open research agenda on this very wide phenomenon - crowdfunding - in light of the very uncertain future of our society and economy after the COVID-19 global pandemic.

Let me start from this second goal which is linked to a kind of personal reflection about the social usefulness of our agenda in banking and finance research, learning and teaching interests or, more broadly, in all the social sciences and management fields. When the call for papers of this issue was issued, the research intention was to point out research trends and policy suggestions about crowdfunding developments in Europe. Due to the new socioeconomic situation Europe and the whole world must cope with after the emergence of the COVID-19 pandemic, the aim and the general research question have become wider in scope: what really is the contribution of crowdfunding to the recovery of the socio-economic environment in the near future? This question is, in my research experience, new with regard to urgence but not in terms of emergence. Since 2015, it was clear to me that (Previati, Galloppo and Salustri, 2015: 22):

[...] crowdfunding is a very recent financial (and social) phenomenon all over the world. When we met at the beginning of our research effort, analysing the different topics and issues arising with reference to crowdfunding, we decided that an interdisciplinary and pluralistic approach was the best path to this phenomenon's understanding, from a theoretical and methodological point of view.

Pluralism and usefulness, from a socio-economic and policy point of view, must drive the answer to the question above. We can find some insights for answering from previous published research analysis, and from those insights we can suggest a (partially) new research agenda for the near future.

Following an increasing stream of research, in terms of number of papers and articles coming from very different social sciences fields (finance, banking, economics, management, marketing, sociology, psychology, and so on), in the last years some international books were published about crowdfunding. Two of them attracted my attention, for different reasons: one is edited by Cumming and Johan (2019) and the other one is edited by Landström, Parhankangas, and Mason (2019). The first is typically a book of entrepreneurial finance; the 
latter is more multidisciplinary, especially in the chapter where the literature and future trends of research are analysed (Bogusz, 2019).

If we consider the two words that are the components of crowdfunding, we identify on the one hand the social profile of the phenomenon (the crowd); on the other, the financial aspects (funding). As all we know, the crisis is always a passage in the life of individuals, groups, organisations and society as a whole. The last (of many other) crisis of our society, driven by the COVID-19 pandemic, clearly underlines that economy and society are strictly interlinked, with all the causes and the effects that should be observed, researched and managed with specific competences and a holistic view of society as a whole, at macro-, meso- and microlevel.

The financial aspects are very important, of course, as well analysed in Cumming and Johan (2019), with many chapters dedicated above all to equity and lending crowdfunding. The consequent relevance of new rules to organise better these financing channels is fundamental, and new regulation is emerging at European level (Cumming and Johan, 2019: 451):

Crowdfunding has enormous potential, and public policy and regulation that is well designed can keep this potential on track to enable the financing of new innovations to the benefit of entrepreneurs, portals, investors, and society at large.

We need more research to understand better and better the supply and the demand side in the two-sided crowdfunding market (the same is for donation and reward crowdfunding), in the social and for-profit segments of the market, from different perspectives: psycho-social, technological, legal, organisational and strategic (business models). And I believe that every of our findings must support better policies at government level, at financial industry level and at enterprise or non-profit organisation level. Our research must be rooted in the real world of business and policy decisions, not only for our publishing (or for publishing companies) interests. Some great research questions, from this point of view, after the COVID19 pandemic, are the following: can the development of crowdfunding platforms sustain the recovery of SME's all over the world? Are the financial and technological competences of households and enterprises sufficient to favour a matching between seekers and investors? Can an open crowdfunding market at European level help this matching?

Moreover, I think that we cannot limit our efforts to the financial perspective alone. Crowdfunding goes beyond financial capital, and this is true especially nowadays. Human and social capitals are strictly connected to the financial, not only in crowdfunding markets, as demonstrated by the financial history of societies (think, for instance, of the history of the banks!). As Bogusz (2019: 38) maintains, "[f]uture research in this area could examine the role of other forms of capital in crowdfunding, and whether such forms of capital differ in this predominantly online environment". Soft information profiles of assessment process supported by platforms and taken into consideration by investors are the clear demonstration of the necessity of refocusing our scholarly attention on cooperation and trust. Information asymmetries and agency problems are not only caused by information flows and assessment models, but basically by the quality of social and power relationships between actors in twosided markets.

Crowdfunding is more a matter of trust and social values, also in equity and lending cases, than we commonly assume. 
Especially in moments of crisis like the one we are currently experiencing, it is useful to investigate once more the drivers of crowdfunding and try to understand the socio-economic variables affecting the development of this phenomenon in different contexts (e.g., countries, industries, communities). I apologise for quoting my own work, but it seems indeed very true nowadays that (Previati, Galloppo and Salustri, 2015: 30):

Crowdfunding appears as a mix of innovation, technology, and entrepreneurship to create opportunities for job creation and poverty reduction. Specifically, crowdfunding is a function of all of these socio-economic trends and we want to define an indicator of crowdfunding activity which takes account of these drivers.

From a methodological point of view, a more open (not only focused on traditional and nonmanagerial approaches to banking and finance topics) research agenda, needs approaches not only from a distance, based on dataset created by analysing platforms, but also from within, studying real cases and processes. It is worth noting that this approach is followed also in entrepreneurial finance contributions (Cumming and Johan, 2019). Nowadays, also the Nobel Prize winner in Finance, Robert J. Shiller (2019), underlines the relevance of narrative economics: we need more stories to genuinely understand crowdfunding, too.

After this brief introduction, I would like to succinctly introduce the articles in this issue, starting with the one by Striano, which is linked to the sense of crowdfunding as an artefact of a new world, in which different actors share a common vision of this new world, exploiting the opportunities offered by technology for their own goals in a reciprocal way, and at the same time, developing a different identity, in some respects, from that expressed by traditional financing and investing modes. Crowdfunding emerges from crowdsourcing, a new way to cooperate through digital technology: from this point of view, it represents a new way to manage financial needs of seekers and investors, innovating the scenario. The narrative of crowdfunding and crowdsourcing movement was fundamentally sustained by communities that were, in the beginning (around 15 years ago), searching for a new identity in the financial world. At the best of my knowledge, the crowdfunding phenomenon did not produce a manifesto but tried to assert a widespread sense of cultural change in the banking and finance landscape, a new identity of financial exchanges. I can say that crowdfunding has been, in a certain way, a forerunner of the Fintech revolution started at the end of the 2010s of the $21^{\text {st }}$ century. Technology is like youth for "La Voce" and "La Diana", a dogma on which the sense of identity of crowdfunding and Fintech communities is built in the financial world, trying to change the reality of finance within a digital world.

The article by Battaglia, Manganiello and Ricci (Is Equity Crowdfunding the Land of Promise for Female Entrepreneurship?), through a dataset of 626 equity crowdfunding campaigns in four countries, calls attention to the fact that female entrepreneurs seem to have better results in this type of funding endeavours, due to some specific communication competences. There is increasing evidence that perception and cultural values influence the investors' choice to support more female rather than male entrepreneurs, especially in those countries where the gender gap is wider. The adoption of a micro-perspective (e.g., through case studies) is suggested for further research on the topic, so as to better understand the drivers and, therefore, the features of the investing process that brings advantages to female entrepreneurs. Following this stream of research, it may be interesting to study other kind of gender gaps, where gender intersects with other aspects of the entrepreneurial personhood (e.g., migrants), 
adopting first a qualitative approach (i.e., case studies) to identify the most important factors influencing the degree of success of crowdfunding campaigns (equity and debt, too), and then to try and build a dataset for more extensive validation of drivers.

The article by Enrico Battisti, Elvira Anna Graziano, Yam B. Limbu, Gian Paolo Stella (Web 2.0 and Equity Crowdfunding: A Social Network Analysis) investigates the relationship between equity crowdfunding and social media. The literature is still scarce, and no studies have jointly investigated these topics in Italy. As a result, the study here presented aims at investigating, through an exploratory quantitative research approach based on a Social Network Analysis (SNA) methodology, the role that equity crowdfunding platforms play on social media, specifically on Twitter. The results of the study indicate that an increasing number of tweets and users discuss online equity crowdfunding following the introduction of the Consob Regulation no. 20264 (17/01/2018) on equity crowdfunding and the growth of the use of this instrument in the first quarter of 2019. The role of informal networks on social media in influencing equity crowdfunding campaigns is an interesting topic under scrutiny in this paper. Also in this case, a mixed research method (from a distance using social media dataset, and from within using focus group interviews about specific campaigns) could help to describe better the processes underlying the campaigns and the relative success drivers.

The investigation by Boletta, Giuffrida and Giudici (When the Crowd Is Too Crowdy: The Relationship between the Number of Investors and Follow-Up Company Growth in Equity Crowdfunding) tests the so-called 'curse of the crowd' hypothesis, according to which a larger number of investors registered at the end of the equity crowdfunding campaign is associated with lower growth in the revenues, in the short run. They posit that this effect is attributable to coordination costs, possible conflicts and low incentive for investors to put effort into valueadding activities. The analysis focuses on 54 issuers, using an econometric OLS model where the dependent variable is the revenue growth of the companies and the independent variable is the number of investors that financed the company. The correlation in the short run could be reverted in the long run: this hypothesis is particularly interesting, and it is worth to discuss in future research, also considering a mixed approach (accounting data and deep case analysis) applied to a longer period of observation.

The article by Thibault Cuénoud (Crowdsourcing as an Opportunity for a Responsible Investment Fund? A French Case Study) addresses the question of whether citizens (crowds) should become more involved in sustainable financing organisations that seek legitimacy and socio-economic efficiency. The research question underpinning this study explores the ability of those responsible for sustainable financing to incorporate these new forms of public involvement and provide appropriate financing for societal challenges. Is it possible for these actors to do this? If so, under what conditions? and how will they have to evolve? A longitudinal case study is carried out to develop a regional ethical, solidarity and crowdfunding investment fund in which the role of the public is clearly defined. The author identifies the range of possibilities in organisational transformations that are taking place amongst sustainable financing actors. Here the focus is on donation crowdfunding, which is different in nature and aim in comparison to lending and equity, and it is treated as a form of crowdsourcing. The longitudinal study approach is well developed and interesting: it could be discussed if a generative, idiographic and transformative perspective (typical of social sciences different than economics and finance) is useful to further the understanding of the processes underlying the equity and the lending crowdfunding, with special attention to the specific kind of participation of actors (citizens) involved as investors, issuers and platform managers. In other 
words, I suggest taking into consideration qualitative research approaches also in studying equity and lending crowdfunding, to have a different (probably better) understanding of the relationships between processes and results of the campaigns, in a complementary way to correlation results.

Finally, and in conclusion, I want to thank all the anonymous referees that have reviewed the papers of this thematic issue. I would also like to express my very great appreciation to all the authors that have revised their papers in light of the reviews received. Last but not least, my grateful thanks are also extended to all the colleagues of PIJ for their kind assistance and help.

\section{References}

Bogusz, C. (2019), "Crowdfunding across Research Fields: An Overview and Suggestions for Future Investigation", in H. Landström, A. Parhankangas and C. Mason (eds), Handbook of Research on Crowdfunding, 23-45, Cheltenham: Edward Elgar Publishing. DOI: $10.4337 / 9781788117210.00007$.

Cumming, D.J., and Johan, S.A. (2019), Crowdfunding: Fundamental Cases, Facts, and Insights, London: Academic Press.

Landström, H., Parhankangas, A., and Mason, C. (eds, 2019), Handbook of Research on Crowdfunding, Cheltenham: Edward Elgar Publishing.

Previati D., Galloppo, G., and Salustri, A. (2015), “The 'Wisdom of the Crowd' as an Antidote to the Credit Crunch: A Preliminary Analysis of Crowdfunding", in E. Beccalli and F. Poli (eds), Lending, Investments and the Financial Crisis, 22-51, London: Palgrave Macmillan. DOI: 10.1057/9781137531018_2.

Shiller, R. (2019), Narrative Economics, Princeton, NJ: Princeton University Press. 